\title{
SODYUM HİDROKSİT (NaOH) VE POTASYUM HİDROKSİT (KOH) KULLANILARAK ÜRETİLEN MISIR YAĞI BİYODİZELLERİNINN OPTİMUM REAKSIYYON PARAMETRELERİNİN KARŞILAŞTIRILMASI
}

\author{
Mert GÜLÜM ${ }^{1}$, Atilla BİLGIN ${ }^{1}$, Abdülvahap ÇAKMAK ${ }^{2}$ \\ ${ }^{1}$ Karadeniz Teknik Üniversitesi, Mühendislik Fakültesi, Makina Müh. Bölümü, 61000 Trabzon \\ ${ }^{2}$ Ondokuz Mayıs Üniversitesi, Kavak Mes. Yük. Okulu, Motorlu Araçlar Tekn. Bölümü, 55850 Samsun \\ gulum@ktu.edu.tr, bilgin@ktu.edu.tr, vahapcakmak61@gmail.com
}

(Geliş/Received: 15.12.2014; Kabul/Accepted: 12.08.2015)

ÖZET

$\mathrm{Bu}$ çalışmada, katalizör olarak sodyum hidroksit $(\mathrm{NaOH})$ ve potasyum hidroksit $(\mathrm{KOH})$ kullanılarak transesterifikasyon reaksiyonuyla üretilebilecek en düşük viskoziteye sahip mısır yağı biyodizellerinin optimum reaksiyon parametrelerinin karşılaştırılması amaçlanmıştır. Bu amaç doğrultusunda sırasıyla katalizör oranı, reaksiyon sıcaklığı, reaksiyon süresi ve alkol/yağ mol oranı gibi transesterifikasyon reaksiyonuna etki eden başlıca parametrelerin söz konusu katalizörler kullanılarak üretilen mısır yağı biyodizellerinin kinematik viskozitelerine ve yoğunluklarına etkileri incelenmiştir. Deneysel çalışma sonuçlarına göre, en düşük viskozitelerin elde edildiği optimum reaksiyon parametreleri, $\mathrm{NaOH}$ kullanılarak üretilen biyodizel için \%0,90 katalizör oran $1,50^{\circ} \mathrm{C}$ reaksiyon sicaklığ 1,60 dakika reaksiyon süresi ve $9: 1$ alkol/yağ mol oranı; $\mathrm{KOH}$ kullanılarak üretilen biyodizel için $\% 1,10$ katalizör oranı, $60^{\circ} \mathrm{C}$ reaksiyon sıcaklığı, 60 dakika reaksiyon süresi ve 9:1 alkol/yağ mol oranı olarak belirlenmiş̧ir. Ayrıca, üretilen en düşük viskoziteli biyodizellerin her ikisinin de yakıt özelliklerinin EN 14214 ve ASTM D 6751 standartlarına uygun olduğu tespit edilmiştir.

Anahtar Kelimeler: Biyodizel, transesterifikasyon reaksiyonu, mısır yağı biyodizeli, viskozite, üretim parametreleri, optimizasyon

\section{COMPARISON OF OPTIMUM REACTION PARAMETERS OF CORN OIL BIODIESELS PRODUCED BY USING SODIUM HYDROXIDE (NaOH) AND POTASSIUM HYDROXIDE (KOH)}

\begin{abstract}
In this study, it was aimed to compare optimum reaction parameters of the lowest kinematic viscosity corn oil biodiesels which can be producible by using sodium hydroxide $(\mathrm{NaOH})$ and potassium hydroxide $(\mathrm{KOH})$ as catalyst and methanol $\left(\mathrm{CH}_{3} \mathrm{OH}\right)$ as alcohol by means of transesterification reaction. Therefore, the effects of main parameters influencing the transesterification reaction such as catalyst concentration, reaction temperature, reaction time, alcohol/oil molar ratio on the kinematic viscosities and densities of produced corn oil biodiesels were investigated. According to experimental results, optimum reaction parameters giving the lowest viscosity were determined as $0,90 \%$ catalyst concentration, $50^{\circ} \mathrm{C}$ reaction temperature, 60 minutes reaction time and 9:1 alcohol/oil molar ratio for biodiesel produced by using sodium hydroxide, and, $1,10 \%$ catalyst concentration, $60^{\circ} \mathrm{C}$ reaction temperature, 60 minutes reaction time and 9:1 alcohol/oil molar ratio for biodiesel produced by using potassium hydroxide. Also, fuel properties of each optimum biodiesels were found in accordance with EN ASTM D 6751 and EN 14214 standards.
\end{abstract}

Keywords: Biodiesel, transesterification reaction, corn oil biodiesel, viscosity, production parameters, optimization 


\section{GİRIŞ (INTRODUCTION)}

Dünyadaki enerji ihtiyacının büyük bir kısmı fosil kökenli yakıtlardan karşılanmaktadır. Bu yakıtların fiyatlarının artması, belirli coğrafyalarda bulunan rezervlerinin gün geçtikçe azalması ve kullanımında meydana gelen emisyonların çevreyi ve insan sağ lığını olumsuz yönde etkilemesi nedeniyle bilim insanları özellikle içten yanmalı motorlarda kullanılabilecek yeni, ekonomik, temiz ve yenilenebilir alternatif yakıtlar üzerinde araştırmalar yapmaktadırlar. Tarımsal potansiyeli yüksek olan ülkemizde termik verimi en yüksek içten yanmalı motor olan dizel motorları için alternatif yenilenebilir yakıt konusunda biyodizel ön plana çıkmaktadır.

Üretiminde kullanılan yağ ve alkol türüne göre değişiklikler göstermekle birlikte, genel olarak biyodizelin bazı üstün özellikleri şu şekilde sıralanabilir: (1) Molekül yapısı dizel yakıtına benzediğinden, dizel motorlarında herhangi bir değişiklik yapılmadan doğrudan ya da dizel yakıtıyla belirli oranlarda karıştırılarak kullanılabilmektedir [1].

(2) Parlama noktası sıcaklığı dizel yakıtına göre daha yüksek olduğundan taşınması ve depolanması daha güvenlidir [2]. (3) Molekül yapısında kütlesel olarak $\% 10-12$ oranlarında oksijen bulunması nedeniyle yanma verimi iyileştiğinden dizel yakıtı kullanımına göre daha az karbon monoksit (CO), yanmamış veya yarı yanmış hidrokarbonlar (HC) ve is emisyonu salınmaktadır [3]. (4) Yağlayıcılık özelliği dizel yakıtına göre daha yüksek olduğundan motor parçalarının ömrünü uzatır [4]. (5) Setan sayısı (4867) dizel yakıtına (40-55) göre daha yüksek olduğundan tutuşma gecikmesi süresi kısalır ve motorun vuruntulu çalışma ihtimali azalır $[5,6]$.

Yukarıda belirtilen birçok üstün özelliklerine karşın biyodizelin bazı yetersizlikleri de vardir: (1) Viskozitesi $\left(40^{\circ} \mathrm{C}\right.$ 'de $\left.3,5-5,0 \mathrm{~mm}^{2} / \mathrm{s}\right)$ dizel yakitına $\left(40^{\circ} \mathrm{C}\right.$ 'de $\left.2,0-3,5 \mathrm{~mm}^{2} / \mathrm{s}\right)$ göre daha yüksektir [7]. (2) Alt 1 sıl değeri $(35-40 \mathrm{MJ} / \mathrm{kg})$ dizel yakıtına $(42,5$ $\mathrm{MJ} / \mathrm{kg}$ ) göre daha düşüktür [6,7]. (3) Bulutlanma ve akma noktası sıcaklıkları dizel yakıtına göre daha yüksek olduğundan soğuk iklimlerde kullanımında ilk harekette bazı sorunlar ortaya çıkabilir [8]. (4) Azotoksit emisyonları $\left(\mathrm{NO}_{\mathrm{x}}\right)$ için ise literatürde farklı değerlendirmeler vardır. Bazı çalışmalarda dizel yakıtına göre daha yüksek azotoksit emisyonları verdiği belirtilirken $[9,10]$, diğer bazı çalışmalarda ise azotoksit emisyonlarını azalttığı görülmüştür $[11,12]$.

Literatürde, en yüksek metil ester verimini elde etmek amaciyla transesterifikasyon reaksiyonu parametrelerinin optimizasyonuna yönelik birçok çalıșma olmasına rağmen [13-15], en düşük viskozitenin elde edildiği parametrelerin belirlenmesine yönelik çalışmalar çok azdır. Bu yüzden, sunulan çalışmada, transesterifikasyon reaksiyonuna etki eden başlıca parametrelerin katalizör olarak sodyum hidroksit $(\mathrm{NaOH})$ ve potasyum hidroksit $(\mathrm{KOH})$ kullanılarak üretilen misır yağı biyodizellerinin viskozitelerine etkileri incelenerek, farklı katalizörler için en düşük viskoziteli mısır yağı biyodizellerinin reaksiyon parametreleri belirlenmiş ve karşılaştırılmıştır. Böylece biyodizelin en önemli sorunlarının başında gelen yüksek viskozite sorununa çözüm getirilmeye çalışılmıştır.

\section{DENEYSEL ÇALIŞMA (EXPERIMENTAL STUDY)}

\subsection{Kimyasal Malzemeler (Chemical Materials)}

Çalışmada, bazik katalizli transesterifikasyon reaksiyonu ile biyodizel üretimi için hammadde olarak marketten temin edilen rafineri mısır yağı, katalizör olarak $\mathrm{NaOH}$ ve $\mathrm{KOH}$, alkol olarak ise \%99,8 saflıktaki metil alkol kullanılmıştır. Kullanılan mısır yağının $40^{\circ} \mathrm{C}^{\prime}$ deki kinematik viskozitesi $34,502 \mathrm{cSt}, \quad 15^{\circ} \mathrm{C}$ 'deki yoğunluğu $922,35 \mathrm{~kg} / \mathrm{m}^{3}$ olarak belirlenmiştir.

\section{2 Üretim Parametreleri ve Ölçümler (Production Parameters and Measurements)}

Üretilen biyodizelin fiziksel ve kimyasal özellikleri üretim aşamasındaki çeşitli parametreler tarafindan önemli ölçüde etkilenmektedir. Deneyler sırasında, katalizör olarak yağın kütlece $\% 0,25,0,50,0,75,0,90$, $1,00,1,10,1,25$ ve 1,50 oranlarında $\mathrm{NaOH}$ ve $\mathrm{KOH}$ kullanılmıştır. Ayrıca, reaksiyon sıcaklığı 40, 50, 60, $70^{\circ} \mathrm{C}$; reakiyon süresi $30,60,90,120$ dakika ve alkol/yağ mol oranı 3:1, 6:1, 9:1, 12:1 şeklinde değiştirilmiştir. Değerler literatürdeki parametre aralıklarını kapsayacak şekilde belirlenmiştir [16-18].

Biyodizel üretimi, yoğunluk ve viskozite ölçümleri Karadeniz Teknik Üniversitesi, Makina Mühendisliği Bölümü'nde gerçekleştirilmiştir. Üretilen biyodizellerin yağ asidi metil ester içerikleri Mustafa Kemal Üniversitesi Fen Bilimleri Araştırma ve Uygulama Merkezi'nde, 1909N-133 innowax kapiler kolonlu Hewlett-Packard HP-6890 gaz kromatografisi cihazı ile belirlenmiştir. Yoğunluklar ISO 4787 standardına uygun olarak hassas terazi ve piknometre, dinamik viskoziteler ise HAAKE Düşen Top Viskozimetresi (Falling Ball Viscometer) yardımıyla DIN 53015 standardına uygun olarak ölçülmüştür. Kinematik viskozite değerleri ise aynı sıcaklık için dinamik viskozitenin yoğunluğa bölümü ile belirlenmiştir. Biyodizellerin parlama noktası sıcaklığı (EN ISO 3679), soğukta filtre tıkanma noktası sicaklığı (EN 116) ve üst 1sıl değerleri (DIN 51900-2) Karadeniz Teknik Üniversitesi Prof. Dr. Saadettin GÜNER Yakıt Araştırma ve Uygulama Merkezi’nde ölçtürülmüştür. 


\subsection{Belirsizlik Analizi (Uncertainty Analysis)}

Çalışmada, ölçülen ve hesaplanan büyüklüklerin (yoğunluk ve viskozite) belirsizlik analizi Kline ve McClintock tarafindan önerilen yöntem ile belirlenmiştir [19]. Ölçümlerde kullanılan hassas terazi ve kronometrenin belirsizlikleri sirasıyla $0,1 \mathrm{~g}$ ve $0,01 \mathrm{~s}$ olmak üzere, hesaplanan belirsizlikler $\% 0,0280$ ile \%0,0448 aralığında kalmıştır. Belirsizlik değerleri oldukça düşük düzeyde olduğu için ölçüm değerlerinin oldukça yüksek güvenilirliğe sahip olduğu söylenebilir.

\section{BULGULAR VE TARTIŞMA (RESULTS AND DISCUSSION)}

Parametrik incelemeye katalizör oranının değiştirilmesiyle başlanmıştır. En düşük kinematik viskozitelerin elde edildiği optimum katalizör oranları belirlendikten sonra benzer şekilde sırasıyla reaksiyon sıcaklığı, reaksiyon süresi ve alkol/yağ mol oranı değiştirilerek her bir parametrenin üretilen biyodizellerin viskozitelerine etkileri belirlenmeye çalışılmıştır. Her bir aşamada belirlenen optimum (en düşük viskoziteyi veren) değerler bir sonraki aşamada sabit tutulmuştur. Tüm çalışma boyunca viskozite değerleri $40^{\circ} \mathrm{C}$, yoğunluk değerleri ise $15^{\circ} \mathrm{C}$ 'de ölçülmüştür.

\subsection{Katalizör Oranının Etkileri (Effects of Catalyst Concentration)}

Katalizör oranının etkilerinin incelendiği deneyler sirasinda,

Reaksiyon sıcaklığı: $60^{\circ} \mathrm{C}$

Reaksiyon süresi: 60 dakika

Alkol/yağ mol oranı: 6:1

olarak sabit tutulmuş, katalizör oranı yağın kütlece $\% 0,25,0,50,0,75,0,90,1,00,1,10,1,25,1,50$ 'si olacak şekilde değiştirilmiştir. Üretilen biyodizellerin kinematik viskozite ve yoğunluk değerlerinin katalizör oranına göre değişimleri Şekil 1 ve 2'de verilmektedir.

Şekil 1 incelendiğinde, genel olarak katalizör oranı arttıkça biyodizellerin viskozitelerinin azaldığı, $\mathrm{NaOH}$ kullanımında \%0,90 katalizör oranında 4,219 cSt, $\mathrm{KOH}$ kullanımında ise \%1,10 katalizör oranında 4,094 cSt ile en düşük viskozite değerlerinin elde edildiği, bu oranlardan sonra katalizör oranının artırılmaya devam edilmesi durumunda viskozitelerin de arttığı görülmüştür. Katalizör oranı artırıldıkça, viskozitelerin önce azalıp en düşük değerini aldıktan sonra artmaya başlaması transesterifikasyon reaksiyonunun verimindeki değişim ile açıklanabilir. Bilindiği gibi reaksiyon verimi arttığında üretilen biyodizelin viskozitesi azalmaktadır [20,21]. Her iki katalizör kullanımında da, düşük katalizör oranları için (örneğin \%0,25), yağın yapısında bulunan yă asitleri ile katalizörün reaksiyona girmesi nedeniyle arta kalan az miktarda katalizör reaksiyon süresince (60 dakika) transesterifikasyon reaksiyonunu yeterince katalizleyemediğinden transesterifikasyon reaksiyonunun verimi düşük, üretilen biyodizellerin kinematik viskoziteleri yüksek çıkmıştır. Katalizör oranı artırılmaya devam edildikçe, transesterifikasyon reaksiyonunun verimi artarak üretilen biyodizellerin viskoziteleri azalmış ve belirli katalizör oranı değerlerinde en düşük viskozite değerlerini almıştır. Fakat katalizör oranı daha da artırıldığında, yağın yapısının büyük bir kısmını oluşturan trigliseritler hidrolizlenerek sabunlaşmış ve katalizörün etkinliğini azaltmıştır. $\mathrm{Bu}$ durum, transesterifikasyon reaksiyonunun verimini azaltarak [2] üretilen biyodizelin viskozitesinin artmasına neden olmuştur. $\mathrm{KOH}$ kullanılması durumunda daha yüksek katalizör oranında daha düşük viskoziteli biyodizel elde edilmiştir. $\mathrm{Bu}$ durumun, $\mathrm{NaOH}$ 'a göre $\mathrm{KOH}^{\prime}$ ın transesterifikasyon reaksiyonunu daha iyi katalizlemesinden ve metil alkol içerisinde daha iyi çözünmesinden kaynaklandığı düşünülmektedir. Ayrıca, KOH'ın molekül kütlesinin $(56,106 \mathrm{~g} / \mathrm{mol})$ $\mathrm{NaOH}$ 'a göre $(39,997 \mathrm{~g} / \mathrm{mol})$ daha yüksek olması nedeniyle en düşük viskozitenin elde edilebilmesi için daha yüksek potasyum hidroksit oranının kullanılması gerekmiştir.

Şekil 2 incelendiğinde, genel olarak yoğunluk değerlerinin katalizör oranı ile çok fazla değişmediği görülmüştür. $\mathrm{Bu}$ durum, transesterifikasyon reaksiyonuna giren katalizörün üretilen biyodizelin yapısında bulunmaması (veya çok az bulunması) ve sadece reaksiyonu hizlandirmak ile verimi iyileştirmek için kullanılmasından kaynaklanmaktadır. Diğer taraftan, yoğunluk değerleri, reaksiyon sıcaklığı (Şekil 4), reaksiyon süresi (Şekil 6) ve alkol/yağ mol oranına göre (Şekil 8) de çok fazla değişmemektedir. Bu durum, üretilen biyodizelin yapısında bulunan metil esterlerin yoğunluklarının birbirlerine oldukça yakın olmasının yanında, kütlesel oranlarının da üretim parametrelerine bağlı olarak çok fazla değişmediğini göstermektedir.

\subsection{Reaksiyon Sıcaklığının Etkileri (Effects of Reaction Temperature)}

Reaksiyon sıcaklığının etkilerinin incelendiği deneyler sirasinda,

Katalizör oranı: \%0,90 (NaOH), \%1,10 (KOH)

Reaksiyon süresi: 60 dakika

Alkol/yağ mol oranı: 6:1

olarak sabit tutulmuş, reaksiyon sıcaklığı 40, 50, 60 ve $70^{\circ} \mathrm{C}$ şeklinde değiştirilmiştir. Üretilen biyodizellerin kinematik viskozite ve yoğunluk değerlerinin reaksiyon sıcaklığına göre değişimleri Şekil 3 ve 4'te verilmektedir. 


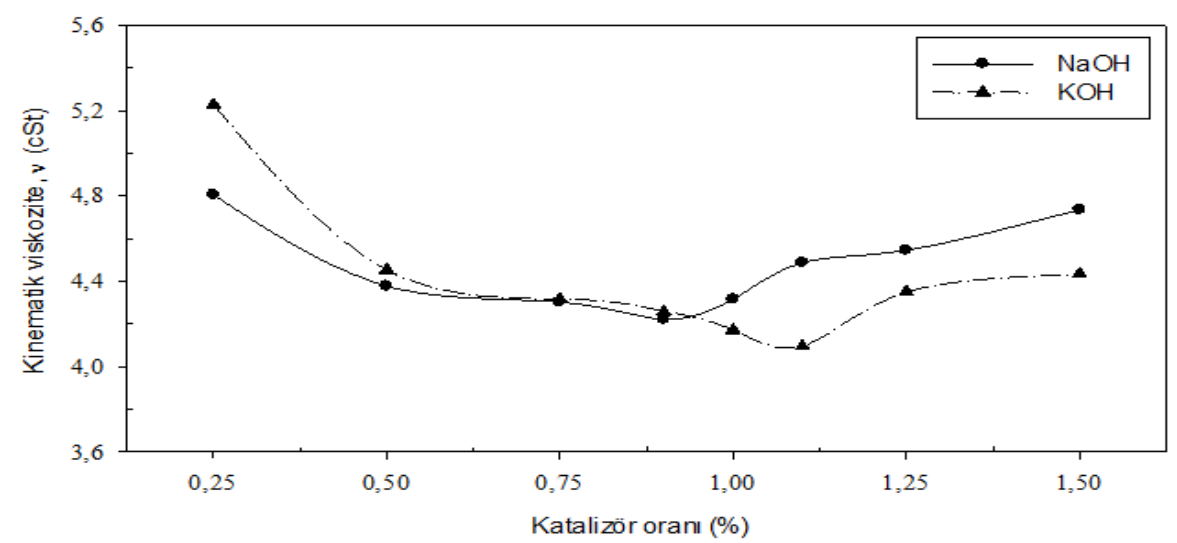

Şekil 1. $\mathrm{NaOH}$ ve KOH kullanılarak üretilen biyodizellerin kinematik viskozitelerinin katalizör oranına göre değişimleri (Changes of kinematic viscosities with respect to catalyst concentration for biodiesels produced by using $\mathrm{NaOH}$ and $\mathrm{KOH})$

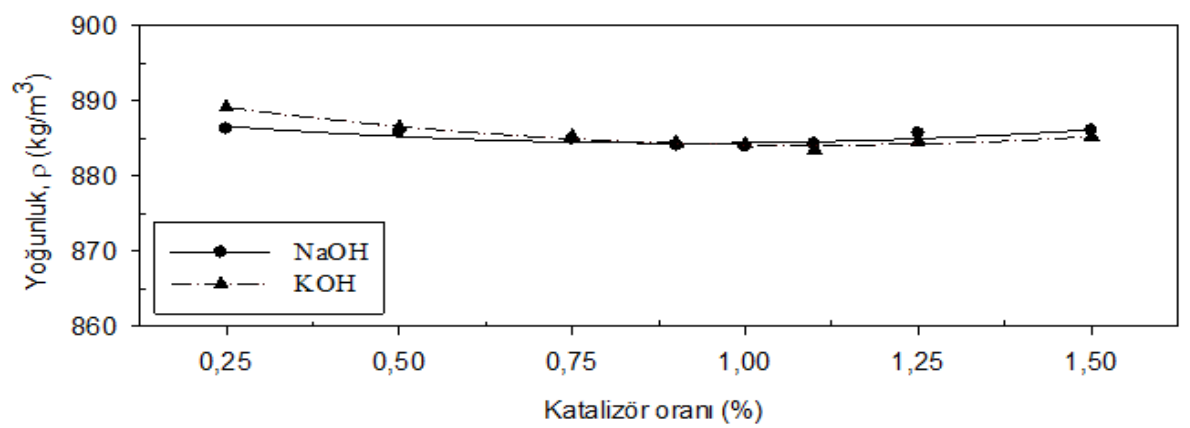

Şekil 2. $\mathrm{NaOH}$ ve $\mathrm{KOH}$ kullanılarak üretilen biyodizellerin yoğunluklarının katalizör oranına göre değişimleri (Changes of densities with respect to catalyst concentration for biodiesels produced by using $\mathrm{NaOH}$ and $\mathrm{KOH}$ )

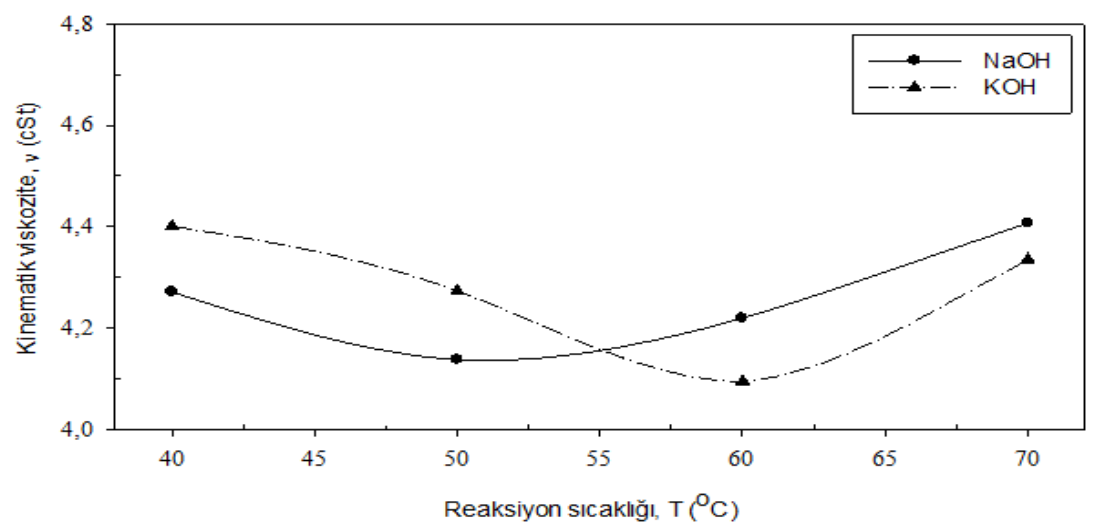

Şekil 3. $\mathrm{NaOH}$ ve $\mathrm{KOH}$ kullanılarak üretilen biyodizellerin kinematik viskozitelerinin reaksiyon sıcaklı̆̆ına göre değişimleri (Changes of kinematic viscosities with respect to reaction temperature for biodiesels produced by using $\mathrm{NaOH}$ and $\mathrm{KOH})$

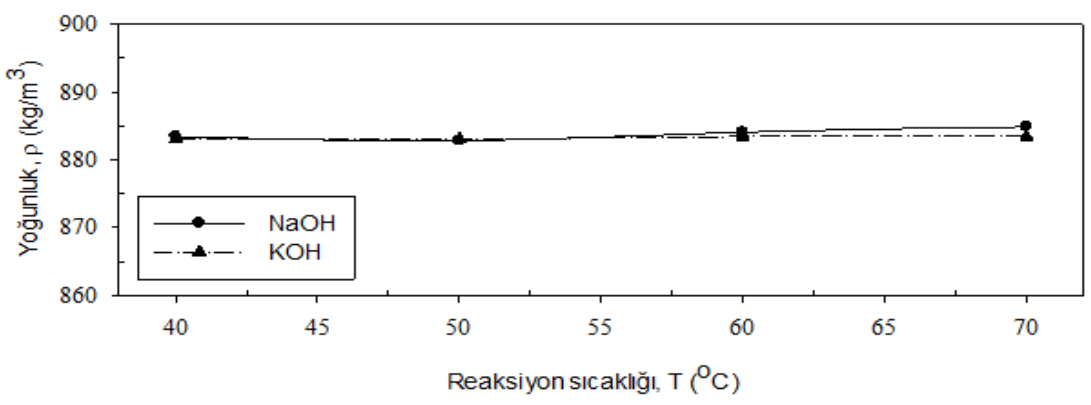

Şekil 4. $\mathrm{NaOH}$ ve $\mathrm{KOH}$ kullanılarak üretilen biyodizellerin yoğunluklarının reaksiyon sıcaklı̆ğına göre değişimleri (Changes of densities with respect to reaction temperature for biodiesels produced by using $\mathrm{NaOH}$ and $\mathrm{KOH}$ ) 
Şekil 3 incelendiğinde, karakteristik olarak reaksiyon sıcaklığı arttıkça üretilen biyodizellerin viskozitelerinin azaldığı, $\mathrm{NaOH}$ kullanımında $50^{\circ} \mathrm{C}$ reaksiyon sicaklığında $4,137 \mathrm{cSt}$, $\mathrm{KOH}$ kullanımında ise $60^{\circ} \mathrm{C}$ reaksiyon sicaklığında 4,094 cSt ile en düşük viskozite değerlerinin elde edildiği, bu sicaklık değerlerinden sonra reaksiyon sıcaklığının artırılmaya devam edilmesi durumunda üretilen biyodizellerin viskozitelerinin artmaya başladığı görülmüştür. Düşük reaksiyon sicaklıklarında transesterifikasyon reaksiyonunun yeterli şekilde tamamlanamaması yüksek viskoziteli biyodizellerin üretilmesine neden olmuştur. Reaksiyon sıcaklığı arttıkça moleküllerin hızının artmasından dolayı transesterifikasyon reaksiyonunun verimi artmış [22] bu durum üretilen biyodizellerin viskozitelerinin azalmasına neden olmuştur. Fakat metil alkolün kaynama noktası sıcaklığı olan $64,5-65^{\circ} \mathrm{C}$ 'den daha yüksek sıcaklıklarda alkol buharlaşarak reaksiyon ortamından ayrıldığı için reaksiyon tamamlanamadığından, reaksiyon sıcaklığının daha da artırılması durumunda üretilen biyodizellerin viskozitelerinin de $\operatorname{arttığ1}$ gözlemlenmiştir.

\subsection{Reaksiyon Süresinin Etkileri (Effects of Reaction Time)}

Reaksiyon süresinin etkilerinin incelendiği deneyler sirasinda,

Katalizör oranı: \%0,90 (NaOH), \%1,10 (KOH)

Reaksiyon sicaklığı: $50^{\circ} \mathrm{C}(\mathrm{NaOH}), 60^{\circ} \mathrm{C}(\mathrm{KOH})$

Alkol/yağ mol oranı: 6:1

olarak sabit tutulmuş, reaksiyon süresi 30, 60, 90 ve 120 dakika şeklinde değiştirilmiştir. Üretilen biyodizellerin kinematik viskozite ve yoğunluk değerlerinin reaksiyon süresine göre değişimleri Şekil 5 ve 6 ' da verilmektedir.
Şekil 5 incelendiğinde, reaksiyon süresi arttıkça üretilen biyodizellerin viskozitelerinin azaldığ 1 , hem $\mathrm{NaOH}$ hem de $\mathrm{KOH}$ kullanımında 60 dakikalık reaksiyon süresi sonunda sirasiyla 4,137 cSt ve 4,094 cSt ile en düşük viskozite değerlerinin elde edildiği, 60 dakikadan sonra artan reaksiyon süresi ile birlikte viskozitelerin yavaşça artarak daha sonra sabit kalma eğilimine girdiği görülmüştür.

Kısa reaksiyon sürelerinde, transesterifikasyon reaksiyonuna yeterli süre verilmediğinden reaksiyonun verimi düşük, üretilen biyodizellerin viskoziteleri yüksek çıkmıştır. Reaksiyon süresi uzadikça reaksiyon verimi artarak üretilen biyodizellerin viskoziteleri azalmıştır [15]. Reaksiyon süresinin aşırı uzaması durumunda önce esterler tekrar hidrolizlenerek sabunlaşmış ve biyodizellerin viskoziteleri artmış, daha sonra ise transesterifikasyon reaksiyonu dengeye ulaştığı için üretilen biyodizellerin viskoziteleri yaklaşık olarak sabit kalmıştır.

\subsection{Alkol/Yăg Mol Oranının Etkileri (Effects of Alcohol/Oil Molar Ratio)}

Alkol/yă mol oranının etkilerinin incelendiği deneyler sirasinda,

Katalizör oranı: \%0,90 (NaOH), \%1,10 (KOH)

Reaksiyon sicaklığı: $50^{\circ} \mathrm{C}(\mathrm{NaOH}), 60^{\circ} \mathrm{C}(\mathrm{KOH})$

Reaksiyon süresi: 60 dakika

olarak sabit tutulmuş, alkol/yağ mol oranı 3:1, 6:1, 9:1 ve 12:1 şeklinde değiştirilmiştir. Üretilen biyodizellerin kinematik viskozite ve yoğunluk değerlerinin mol oranına göre değişimleri Şekil 7 ve 8 'de verilmektedir.

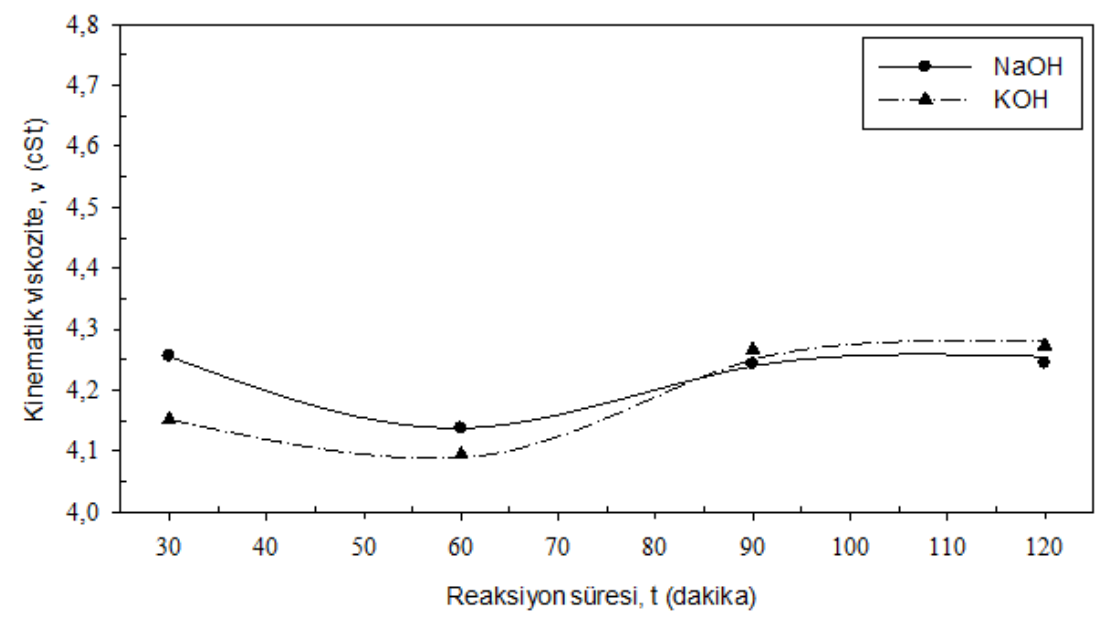

Şekil 5. $\mathrm{NaOH}$ ve $\mathrm{KOH}$ kullanılarak üretilen biyodizellerin kinematik viskozitelerinin reaksiyon süresine göre değişimleri (Changes of kinematic viscosities with respect to reaction time for biodiesels produced by using $\mathrm{NaOH}$ and $\mathrm{KOH}$ ) 


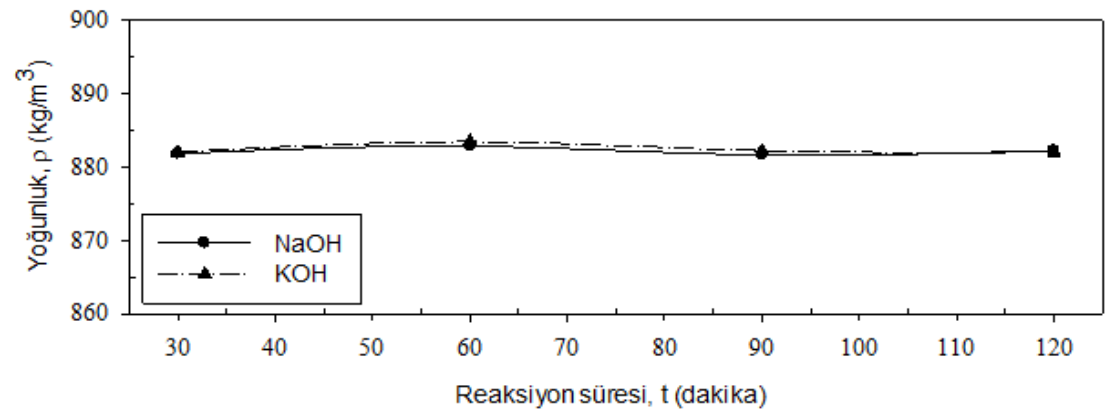

Şekil 6. $\mathrm{NaOH}$ ve $\mathrm{KOH}$ kullanılarak üretilen biyodizellerin yoğunluklarının reaksiyon süresine göre değişimleri (Changes of densities with respect to reaction time for biodiesels produced by using $\mathrm{NaOH}$ and $\mathrm{KOH}$ )

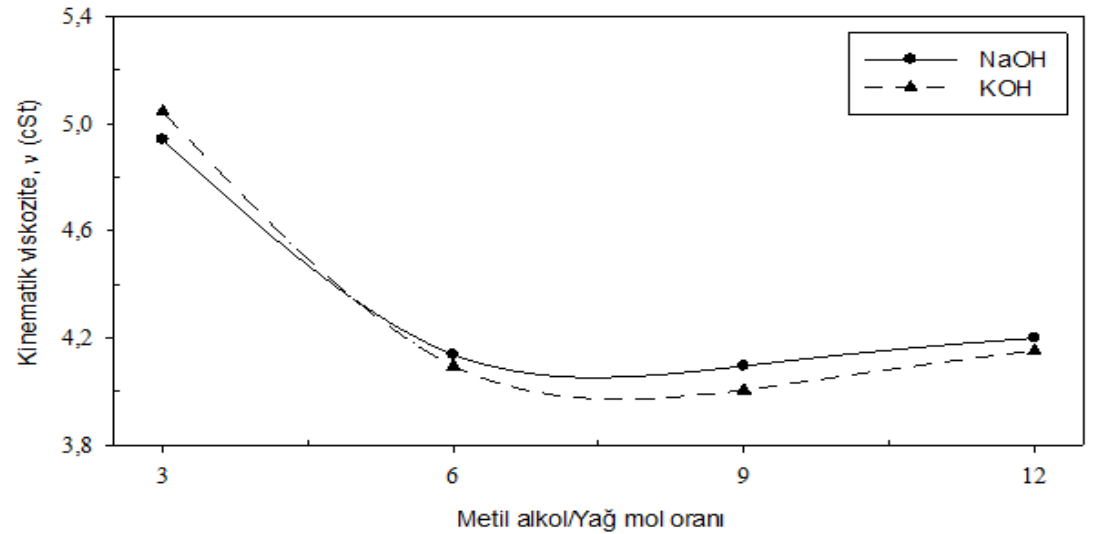

Şekil 7. $\mathrm{NaOH}$ ve $\mathrm{KOH}$ kullanılarak üretilen biyodizellerin kinematik viskozitelerinin metil alkol/yağ mol oranına göre değişimleri (Changes of kinematic viscosities with respect to methyl alcohol/oil molar ratio for biodiesels produced by using $\mathrm{NaOH}$ and $\mathrm{KOH})$

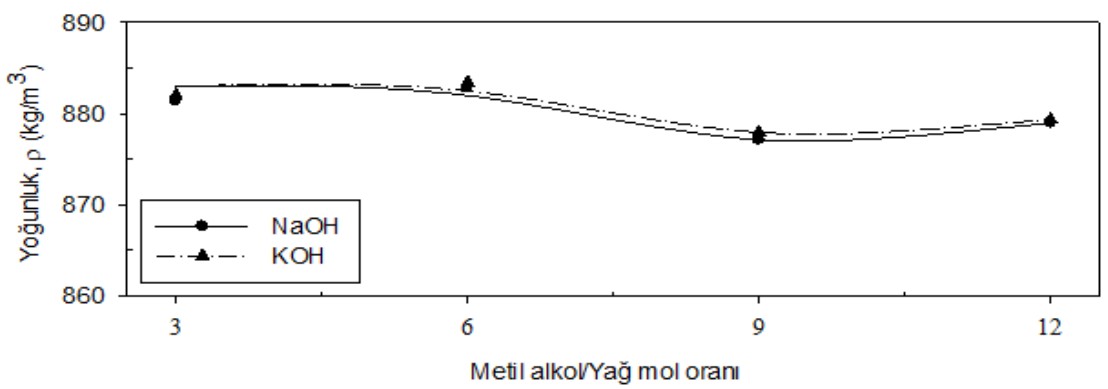

Şekil 8. NaOH ve KOH kullanılarak üretilen biyodizellerin yoğunluklarının metil alkol/yağ mol oranına göre değişimleri (Changes of densities with respect to methyl alcohol/oil molar ratio for biodiesels produced by using $\mathrm{NaOH}$ and $\mathrm{KOH}$ )

Şekil 7 incelendiğinde, mol oranı arttıkça üretilen biyodizellerin viskozitelerinin azaldığı, hem $\mathrm{NaOH}$ hem de KOH kullanımında 9:1 mol oranı için (ölçülen değerler dikkate alındığında) sırasıyla 4,095 cSt ve 4,005 cSt ile en düşük viskozite değerlerinin elde edildiği, 9:1 mol oranından sonra artan mol oranı ile birlikte viskozitelerin yavaşça arttığı görülmüştür. 3:1 alkol/yağ mol oranında en yüksek viskoziteli biyodizellerin elde edildiği, daha fazla alkol kullanıldığında ise, örneğin 6:1 veya 9:1 alkol/yağ mol oranlarında, bir denge reaksiyonu olan transesterifikasyon reaksiyonu ürünler yönüne kaydığg 1 için reaksiyon verimi artarak [23] üretilen biyodizellerin kinematik viskozitelerinin azaldı $\breve{g}_{1}$ belirlenmiştir. Fakat aşırı miktarlarda alkol kullanıldığında, örneğin 12:1 alkol/yağ mol oranında, gliserinin metil ester fazındaki çözünürlüğünün artması, ester fazı ile gliserin fazının ayrışmasının zorlaşması ve reaksiyon sırasında gliserinin ortamda çözünmüş olarak bulunması reaksiyonun yönünü girenler yönüne kaydırdığından transesterifikasyon reaksiyonunun verimi azalıp üretilen biyodizellerin viskozitelerinin arttığı görülmüştür.

Sonuç olarak, en düşük viskozitelerin elde edildiği optimum reaksiyon parametreleri, $\mathrm{NaOH}$ kullanılarak üretilen biyodizel için $\% 0,90$ katalizör oran $1,50^{\circ} \mathrm{C}$ reaksiyon sıcaklığı, 60 dakika reaksiyon süresi ve 9:1 alkol/yağ mol oranı; $\mathrm{KOH}$ kullanılarak üretilen biyodizel için $\% 1,10$ katalizör oran $1,60^{\circ} \mathrm{C}$ reaksiyon sıcaklığı, 60 dakika reaksiyon süresi ve 9:1 alkol/yağ mol oranı olarak belirlenmiştir. 
Tablo 1. Dizel yakıtının ve optimum biyodizellerin bazı yakıt özellikleri (Some fuel properties of diesel fuel and optimum biodiesels)

\begin{tabular}{|c|c|c|c|c|c|c|}
\hline Özellikler & Birimler & Dizel & $\begin{array}{c}\mathrm{NaOH} \\
\text { kullanılarak } \\
\text { üretilen } \\
\text { biyodizel }\end{array}$ & \begin{tabular}{l}
\multicolumn{1}{c}{$\mathrm{KOH}$} \\
kullanılara \\
k üretilen \\
biyodizel
\end{tabular} & EN 14214 & $\begin{array}{l}\text { ASTM } \\
\text { D } 6751\end{array}$ \\
\hline $\begin{array}{l}40^{\circ} \mathrm{C} ' \mathrm{de} \\
\text { kinematik } \\
\text { viskozite }\end{array}$ & cSt & 2,700 & 4,095 & 4,005 & $3,50-5,00$ & $1,90-6,00$ \\
\hline $\begin{array}{l}15^{\circ} \mathrm{C} \text { 'de } \\
\text { yoğnnluk }\end{array}$ & $\mathrm{kg} / \mathrm{m}^{3}$ & 833,33 & 877,13 & 877,94 & $860-900$ & 1 \\
\hline $\begin{array}{l}\text { Parlama } \\
\text { noktas1 } \\
\text { Sicaklığ } 1\end{array}$ & ${ }^{\circ} \mathrm{C}$ & 63,0 & 169,0 & 171,0 & $101 \leq$ & $130 \leq$ \\
\hline $\begin{array}{l}\text { Soğukta } \\
\text { filtre } \\
\text { tıkanma } \\
\text { noktası } \\
\text { Sicaklığ } 1\end{array}$ & ${ }^{\circ} \mathrm{C}$ & $-6,0$ & $-5,0$ & $-4,0$ & $\begin{array}{l}<+5 \text { (yaz) } \\
-15<(\text { kış })\end{array}$ & 1 \\
\hline $\begin{array}{l}\text { Üst 1sil } \\
\text { değer }\end{array}$ & $\mathrm{kJ} / \mathrm{kg}$ & 45950 & 39930 & 39947 & 1 & 1 \\
\hline
\end{tabular}

${ }^{1}$ Belirtilmemiş.

\section{OPTIMUM BIYYDIZELLERİN TÍCARİ DİEL YAKITI ILE KARŞILAŞTIRILMASI (COMPARISON OF OPTIMUM BIODIESELS WITH COMMERICAL DIESEL FUEL)}

Tablo 1'de ticari dizel yakıtı ile yukarıda belirlenen optimum reaksiyon koşulları kullanılarak üretilen en düşük viskoziteye sahip biyodizellerin yakıt özellikleri verilmiştir. Söz konusu tablo incelendiğinde, biyodizellerin yakıt özelliklerinin EN 14214 ve ASTM D 6751 standartlarına uygun olduğu tespit edilmiştir.

Tablo 2'de ise en düşük viskoziteli biyodizellerinin ortalama molekül kütleleri, kapalı formülleri, yağ asidi türleri ve kütlesel yüzde içerikleri verilmiştir.

Tablo 2. Optimum biyodizellerin ortalama molekül kütleleri, kapalı formülleri, yă̆ asidi türleri ve kütlesel yüzde içerikleri (Average molecular masses, closed formulas, fatty acid types and mass percentage contents of optimal biodiesels)

\begin{tabular}{|l|c|c|}
\cline { 2 - 3 } \multicolumn{1}{c|}{} & \multicolumn{2}{c|}{ Kütlesel yüzde bileşimi, \% } \\
\hline Yağ asidi türü & $\begin{array}{c}\text { NaOH } \\
\text { kullanılarak } \\
\text { üretilen } \\
\text { biyodizel }\end{array}$ & $\begin{array}{c}\mathrm{KOH} \\
\text { kullanilarak } \\
\text { üretilen } \\
\text { biyodizel }\end{array}$ \\
\hline Palmitik (C16:0) & 15,190 & 20,278 \\
\hline Oleik (C18:1) & 46,954 & 47,184 \\
\hline Linoleik (C18:2) & 34,243 & 29,575 \\
\hline $\begin{array}{l}\alpha \text {-Linolenik asit } \\
\text { (C18:3) }\end{array}$ & 1,276 & 1,077 \\
\hline Araşidik (C20:0) & 0,754 & 0,972 \\
\hline Gadoleik asit (C20:1) & 0,657 & 0,445 \\
\hline Behenik (C22:0) & 0,487 & 0,369 \\
\hline Lignoserik (C24:0) & 0,439 & 0,101 \\
\hline $\begin{array}{l}\text { Ortalama molekül } \\
\text { kütlesi, g/mol }\end{array}$ & $292,87{ }^{1}$ & $291,27^{1}$ \\
\hline Kapalı formülü & $\mathrm{C}_{18,77} \mathrm{H}_{35,16} \mathrm{O}_{2}{ }^{1}$ & $\mathrm{C}_{18,66} \mathrm{H}_{35,13} \mathrm{O}_{2}{ }^{1}$ \\
\hline
\end{tabular}

Yağ asidi türü ve içeriklerinden hesaplanmıştır.

\section{SONUÇLAR (CONCLUSIONS)}

$\mathrm{Bu}$ çalışmada, katalizör olarak sodyum hidroksit $(\mathrm{NaOH})$ ve potasyum hidroksit $(\mathrm{KOH})$ kullanılarak transesterifikasyon reaksiyonuyla üretilebilecek en düşük viskoziteli mısır yağı biyodizellerinin optimum reaksiyon parametrelerinin belirlenmesi ve karşılaştırılması amaçlanmıştır. Elde edilen sonuçlar aşağıdaki gibi özetlenebilir:

Mısır yağ1 ve sodyum hidroksit kullanılarak gerçekleştirilen transesterifikasyon reaksiyonlarında $40^{\circ} \mathrm{C}$ 'deki en düşük kinematik viskozite değeri, $\% 0,90$ katalizör oran $1,50^{\circ} \mathrm{C}$ reaksiyon sicaklığı, 60 dakika reaksiyon süresi ve 9:1 alkol/yăg mol oranı için 4,095 cSt olarak elde edilmiştir.

Mısır yağı ve potasyum hidroksit kullanılarak gerçekleştirilen transesterifikasyon reaksiyonlarında $40^{\circ} \mathrm{C}$ 'deki en düşük kinematik viskozite değeri, $\% 1,10$ katalizör oranı, $60^{\circ} \mathrm{C}$ reaksiyon sicaklığ 1,60 dakika reaksiyon süresi ve 9:1 alkol/yağ mol oranı için 4,005 cSt olarak elde edilmiştir.

Yukarıda belirtilen şartlarda üretilen biyodizellerin viskozite değerleri, literatürdeki bazik katalizör kullanılarak üretilen birçok biyodizellerin kinematik viskozite değerlerinden daha düşüktür [24-28].

Üretim parametrelerinin biyodizellerin yoğunluk değerleri üzerinde çok fazla etkili olmadığı, yoğunlukların yaklaşık olarak sabit kaldığı görülmüştür. Bu durum, üretilen biyodizelin yapısında bulunan metil esterlerin yoğunluklarının birbirlerine oldukça yakın olmasının yanında, kütlesel oranlarının da üretim parametrelerine bağlı olarak çok fazla değişmediğini göstermektedir.

Sodyum hidroksit kullanılarak üretilen optimum biyodizelin ortalama molekül kütlesi ve kapalı formülü $292,87 \mathrm{~g} / \mathrm{mol}$ ve $\mathrm{C}_{18,77} \mathrm{H}_{35,16} \mathrm{O}_{2}$; potasyum 
hidroksit kullanılarak üretilen optimum biyodizelin ortalama molekül kütlesi ve kapalı formülü ise 291,27 $\mathrm{g} / \mathrm{mol}$ ve $\mathrm{C}_{18,66} \mathrm{H}_{35,13} \mathrm{O}_{2}$ olarak belirlenmiştir.

\section{SEMBOLLER VE KISALTMALAR (SYMBOLS} AND ABBREVIATIONS)

$\rho \quad:$ Yoğunluk $\left(\mathrm{kg} / \mathrm{m}^{3} \equiv \mathrm{g} / \mathrm{L}\right),\left(\mathrm{g} / \mathrm{cm}^{3}\right)$

$v$ : Kinematik viskozite $\left(\mathrm{cSt} \equiv \mathrm{mm}^{2} / \mathrm{s}\right)$

\section{TEŞEKKÜR (ACKNOWLEDGEMENT)}

Bu çalışma, Karadeniz Teknik Üniversitesi Bilimsel Araştırma Projeleri Koordinasyon Birimi (BAP) tarafindan 9745 kodlu proje ile desteklenmiştir.

\section{KAYNAKLAR (REFERENCES)}

1. Özsezen, A.N. ve Çanakçı, M., "Atık Kızartma Yağından Elde Edilen Metil Esterin Ön Yanma Odalı Bir Dizel Motorda Kullanımının Performans ve Emisyonlara Etkisinin İncelenmesi", Journal of The Faculty of Engineering and Architecture of Gazi University, Cilt 23, No 2, 395-404, 2008.

2. Encinar, J.M., González, J.F. ve Reinares, A.R., "Biodiesel from Used Frying Oil. Variables Affecting the Yields and Characteristics of the Biodiesel”, Ind. Eng. Chem. Res., Cilt 44, No 15, 5491-5499, 2005.

3. Aktaş, A. ve Sekmen, Y., "Biyodizel ile Çalışan Bir Dizel Motorda Yakıt Püskürtme Avansının Performans ve Egzoz Emisyonlarına Etkisi”, Journal of The Faculty of Engineering and Architecture of Gazi University, Cilt 23, No 1, 199-206, 2008.

4. Knothe, G. ve Steidley, K.R., "Lubricity of Components of Biodiesel and Petrodiesel. The Origin of Biodiesel Lubricity", Energy\&Fuels, Cilt 19, No 3, 1192-1200, 2005.

5. Ramadhas, A.S., Jayaraj, S., Muraleedharan, C. ve Padmakumari, K., "Artificial Neural Networks Used for the Prediction of the Cetane Number of Biodiesel", Renewable Energy, Cilt 31, No 15, 2524-2533, 2006.

6. Pulkrabek, W.W., Engineering Fundamentals of the Internal Combustion Engine, PrenticeHall, New Jersey, A.B.D., 1997.

7. Kaya, C., Bitkisel Yağlardan Biyodizel Üretimi, Yüksek Lisans Tezi, Dicle Üniversitesi, Fen Bilimleri Enstitüsü, 2006.

8. Alptekin, E. ve Canakci, M., "Determination of the Density and the Viscosities of BiodieselDiesel Fuel Blends", Renewable Energy, Cilt 33, No 12, 2623-2630, 2008.

9. Zhu, L., Zhang, W., Liu, W. ve Huang, Z., "Experimental Study on Particulate and $\mathrm{NO}_{\mathrm{x}}$ Emissions of a Diesel Engine Fueled with Ultra Low Sulfur Diesel, RME-Diesel Blends and PME-Diesel Blends", Science of The Total Environment, Cilt 408, No 5, 1050-1058, 2010.
10. Ghai, S., Das, L.M. ve Babu, M.K.G., "Emissions and Performance Study with Sunflower Methyl Ester as Diesel Engine Fuel", ARPN Journal of Engineering and Applied Sciences, Cilt 3, No 5, 75-80, 2008.

11. Ng, J.H., Ng, H.K. ve Gan, S., "Characterisation of Engine-Out Responses from a Light-Duty Diesel Engine Fuelled with Palm Methyl Ester (PME)", Applied Energy, Cilt 90, No 1, 58-67, 2012.

12. Department of Agriculture Philippine Coconut Authority Web Sitesi, Çevrimiçi: http://www.pure-

essence.biz/site/biodiesel_iec_1_.pdf, Son Erişim Tarihi: 9 Kasım 2014.

13. Çetinkaya, M. ve Karaosmanoğlu, F., "Optimization of Base-Catalyzed Transesterification Reaction of Used Cooking Oil”, Energy\&Fuels, Cilt 18, No 6, 1888-1895, 2004.

14. Anastopoulos, G., Zannikou, Y., Stournas, S. ve Kalligeros, S., "Transesterification of Vegetable Oils with Ethanol and Characterization of the Key Fuel Properties of Ethyl Esters", Energies, Cilt 2, No 2, 362-376, 2009.

15. Satyanarayana, M. ve Muraleedharan, C., "A Comparative Study of Vegetable Oil Methyl Esters (Biodiesels)", Energy, Cilt 36, No 4, 2129-2137, 2011.

16. Atabani, A.E., Silitonga, A.S., Badruddin, I.A., Mahlia, T.M.I., Masjuki, H.H. ve Mekhilef, S., "A Comprehensive Review on Biodiesel as an Alternative Energy Resource and Its Characteristics", Renewable and Sustainable Energy Reviews, Cilt 16, No 4, 2070-2093, 2012.

17. Enweremadu, C.C. ve Mbarawa, M.M., "Technical Aspects of Production and Analysis of Biodiesel from Used Cooking Oil-A Review", Renewable and Sustainable Energy Reviews, Cilt 13, No 9, 2205-2224, 2009.

18. Leung, D.Y.C., Wu, X. ve Leung, M.K.H., "A Review on Biodiesel Production Using Catalyzed Transesterification", Applied Energy, Cilt 87, No 4, 1083-1095, 2010.

19. Holman, J.P., Experimental Methods for Engineers, McGraw-Hill, New York, A.B.D, 2001.

20. Ghanei, R., Moradi, G.R., Taherpourkalantari, R. ve Arjmandzadeh, E., "Variation of Physical Properties During Transesterification of Sunflower Oil to Biodiesel As an Approach to Predict Reaction Progress", Fuel Processing Technology, Cilt 92, No 8, 1593-1598, 2011.

21. Moradi, G.R., Dehghani, S. ve Ghanei, R., "Measurements of Physical Properties During Transesterification of Soybean Oil to Biodiesel for Prediction of Reaction Progress", Energy 
Conversion and Management, Cilt 61, No 1, 67-70, 2012.

22. Hoque, M.D.E., Singh, A. ve Chuan, Y.L., "Biodiesel from Low Cost Feedstocks: The Effects of Process Parameters on the Biodiesel Yield", Biomass and Bioenergy, Cilt 35, No 4, 1582-1587, 2011.

23. El-Sabagh, S.M., Keera, S.T. ve Taman, A.R., "The Characterization of Biodiesel Fuel from Waste Frying Oil", Energy Sources, Cilt 33, No 5, 401-409, 2011.

24. Çildir, O. ve Çanakçı, M., "Çeşitli Bitkisel Yağlardan Biyodizel Üretiminde Katalizör ve Alkol Miktarının Yakıt Özellikleri Üzerine Etkisinin İncelenmesi”, Journal of The Faculty of Engineering and Architecture of Gazi University, Cilt 21, No 2, 367-372, 2006.

25. Yavuz, H., Aksoy, F., Bayrakçeken, H. ve Baydır, Ş.A., "Değişik Bitkisel Yağ Metil
Esterlerinin Üretilmesi, Fiziksel ve Kimyasal Özelliklerinin Karşılaştırılması", Makine Teknolojileri Elektronik Dergisi, Cilt 2, No 1, 23-30, 2008.

26. Ibeto, C.N., Ofoefule, A.U. ve Ezugwu, H.C., "Analytical Methods for Quality Assessment of Biodiesel from Animal and Vegetable Oils", Trends in Applied Sci. Res., Cilt 6, No 6, 537553, 2011.

27. Sivaramakrishnan, K. ve Ravikumar, P., "Determination of Higher Heating Value of Biodiesels", International Journal of Engineering Science and Technology, Cilt 3, No 11, 7981-7987, 2011.

28. Özcanlı, M., Keskin, A. ve Aydın, K., "Biodiesel Production from Terebinth (Pistacia Terebinthus) Oil and Its Usage in Diesel Engine", International Journal of Green Energy, Cilt 8, No 5, 518-528, 2011. 
